\title{
Water flow in tide- and wave-dominated beds of the seagrass Thalassia testudinum
}

\author{
Evamaria W. Koch ${ }^{1, *}$, Giselher Gust ${ }^{2}$ \\ ${ }^{1}$ Horn Point Laboratory, University of Maryland Center for Environmental Science, PO Box 775, Cambridge, \\ Maryland 21613, USA \\ ${ }^{2}$ Technische Universität Hamburg-Harburg, Lauenbruch-Ost 1, D-21079 Hamburg, Germany
}

\begin{abstract}
Biological processes in seagrass meadows are regulated by the exchange of momentum, heat and mass between the surrounding water and the plants and thus may strongly depend on the characteristics of water flow and turbulence. Comparisons of mean flow profiles, turbulence distribution and mixing in meadows of the seagrass Thalassia testudinum colonizing 2 hydrodynamically different sites (wave-dominated and tide-dominated) suggest that the hydrodynamic microclimate and consequently mixing within seagrass beds strongly depend on the hydrodynamic forces (waves and currents) acting on the plants. Unidirectional flows deflect the water over the meadow (skimming flows\}, which potentially leads to lower mixing between the water above and within the meadow. In contrast, waves cause the blades to move back and forth, increasing the exchange between the water column and that within the meadow. Therefore, the hydrodynamic conditions prevailing in the seagrass habitat (waves, tides) change the pattern of flow attenuation and mixing within the vegetation.
\end{abstract}

KEY WORDS: Hydrodynamics - Thalassia testudinum - Currents - Turbulence - Tides - Waves Plant density - Mixing

\section{INTRODUCTION}

The microclimate within canopies of aquatic plants is important to biological processes and is regulated by the exchange of momentum, heat and mass between the surrounding water and the plants (Burke 1982). For example, the rate of mass exchange which determines the concentration and residence time of carbon and nutrients in a seagrass meadow, strongly depends on the hydrodynamic characteristics, particularly the level of turbulence (see Anderson \& Charters 1982). Seagrass beds could benefit from increased flow and turbulence due to faster removal of undesired substances (both by advection and turbulent diffusion) and intensified transport of carbon and nutrients from the water column, through the blade boundary layer, to the leaf surface (Gerard \& Mann 1979, Wheeler 1980, Fonseca \& Kenworthy 1987, Koehl \& Alberte 1988, Koch 1994). Therefore, the ability of seagrasses to attenuate waves

·E-mail: koch@hpl.umces.edu
(Ward et al. 1984, Fonseca \& Fisher 1986, Fonseca \& Cahalan 1992, Verduin 1996, van Keulen 1997) and to decrease current velocities (Fonseca et al. 1982, Fonseca \& Fisher 1986, Clarke 1987, Heller 1987, Gambi et al. 1990, van Keulen 1997) seems to be contradictory to the needs of seagrass populations. However, reduced flow and turbulence within seagrass beds may also result in: (1) accumulation of organic matter leading to the fertilization of the sediment (Kenworthy et al. 1982), (2) reduced porewater flux promoting anaerobic processes (armmonium is the form of nitrogen most readily assimilated by seagrasses; Short 1987) and (3) increased light availability due to deposition of particulate matter (Ward et al. 1984, also see Orth \& Moore 1983, Cambridge \& McComb 1984, Giesen et al. 1990, Zimmerman \& Alberte 1991)

Although hydrodynamic characteristics of seagrass habitats have a wide range of positive and negative biological effects on the vegetation, the water flow in these environments is not well understood. Recent studies identified that flow within seagrass beds is a function of plant movement (Ackerman \& Okubo 1993, 
Verduin 1996), and architecture (3-dimensional structure) of the meadow (Koch 1996, Nepf et al. 1997) while other studies (Worcester 1995, Nepf et al. 1997, van Keulen 1997) suggest that shoot density needs to be taken into consideration when studying the water flow through vegetated areas. Flume experiments suggest that highly turbulent flows result from the presence of seagrass blades (Heller 1987, Gambi et al. 1990). The same observation was found in field studies, especially for the top of the meadow (Grizzle et al. 1996, Verduin 1996). Most studies focus on medium to high seagrass densities because low seagrass densities (100 to 200 shoots $\mathrm{m}^{-2}$ ) may have no effect on turbulent mixing (Worcester 1995). However, in low densities of stiff shoot-like structures (200 'shoots' $\mathrm{m}^{-2}$ ), wakes/turbulence were found to increase linearly (Nepf et al. 1997) while at high 'shoot' densities (2000 'shoots' $\mathrm{m}^{-2}$ ), wakes/turbulence decrease due to enhanced attenuation in current velocity by the vegetation (Nepf et al. 1997). The above studies focus on turbulence in general. Specific turbulence frequencies were observed to be rescaled from low to high frequencies in a seagrass bed with 450 shoots $\mathrm{m}^{-2}$, perhaps leading to a biologically more relevant turbulence frequency (Koch 1996). Although shoot density appears to be an important consideration in studies of hydrodynamics of seagrass beds (van Keulen 1997), the wide range of densities found in situ makes this type of study difficult. We suggest the use of a modified dimensionless number (Richardson number) which takes seagrass shoot density into consideration to evaluate mixing potential in seagrass beds.

Flow within seagrass beds is a function of the hydrodynamic conditions (waves, tides, currents) prevailing in the area. The present study seems to be the first to compare the hydrodynamic conditions in a wave-dominated and a tide-dominated site colonized by the same seagrass species. We questioned if waves and tides can modify the pattern of water flow through Thalassia testudinum beds and, consequently, how this affects mixing of the water masses above and within vegetation of different shoot densities. The data is then put into an ecological context

\section{METHODS}

Time-series of current speeds at different heights within and above seagrass canopies were recorded simultaneously in situ at a $5 \mathrm{~Hz}$ frequency (previously shown to accurately resolve speeds and waves in plant colonized estuarine environments; Leonard \& Luther 1995) using a microprocessor-controlled autonomous data-logger (TattleTale Model 6, Onset Computers, Pocasset, MA) and hot-film sensors (Gust 1988, 1991).
The sensors (built by the authors and also used by Leonard \& Luther 1995) were positioned in vertical arrays and placed within the seagrass beds (Fig. 1). The 4 sensors in the vertical array were located immediately above the sediment surface $(5 \mathrm{~cm})$ to heights within $(10 \mathrm{~cm})$, at the top $(20 \mathrm{~cm})$ and above $(40 \mathrm{~cm})$ the meadow (Fig. 1).

The voltage output of the sensors was calibrated in front of a nozzle at known velocities and temperatures (every $0.2^{\circ} \mathrm{C}$ for the range of temperatures recorded at a $5 \mathrm{~Hz}$ frequency during the deployments). Velocities ranging from 0.8 to $36.9 \mathrm{~cm} \mathrm{~s}^{-1}$ were generated in a temperature controlled water bath by pumping water at a known flow rate $\left(\mathrm{cm}^{3} \mathrm{~min}^{-1}\right)$ through a nozzle of known area $\left(2.16 \mathrm{~cm}^{2}\right)$. Flow velocities were calculated by dividing the flow rate by the nozzle area. Calibration curves (speed vs voltage) were obtained from the voltage output at the different combinations of temperature and velocity (repeatability above $90 \%$ ). Flows higher than $36.9 \mathrm{~cm} \mathrm{~s}^{-1}$ were inferred from the calibration curve.

Fluctuations in water height (waves and tides) were recorded concurrently with horizontal flow speeds, at a $5 \mathrm{~Hz}$ frequency, by a 15 PSI pressure transducer (Model P21LA-276, Transmetrics, Solon, OH) located on the sediment surface within the seagrass meadow, less than $5 \mathrm{~m}$ from the hot-film sensors. Depths were calculated from a factory-provided equation relating voltage output (generated by the pressure transducer according to the water pressure) and depths, using software packages (Statgraphics 2.15, Magnugistics, Inc and TattleTools 1.2, Onset Computers, Pocasset, MA).

In situ data was collected within Thalassia testudinum beds at 2 sites in Florida, USA, (Fig. 2): a wavedominated (Summerland Key, 24 $39^{\prime}$ N, $81^{\circ} 26^{\prime}$ W), and a tide-dominated environment (St. Joseph Bay, $29^{\circ} 42^{\prime} \mathrm{N}, 85^{\circ} 22^{\prime} \mathrm{W}$ ). During the deployment in

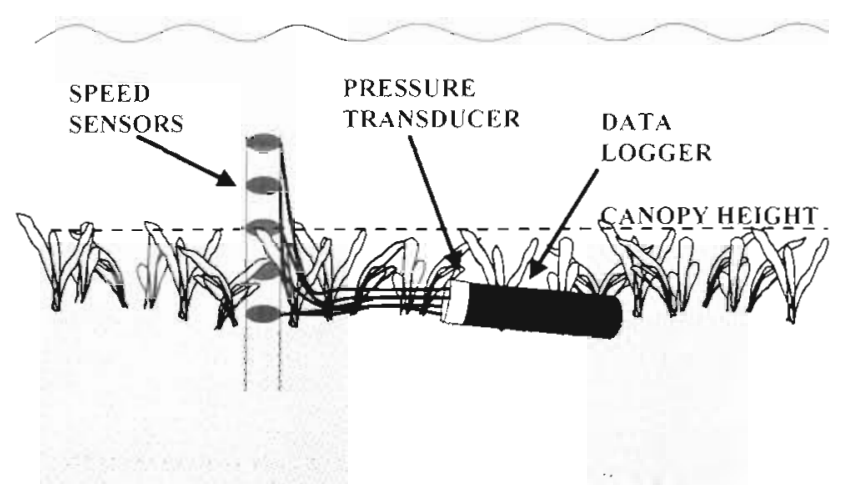

Fig. 1 Deployment of submersible data logger for evaluation of speed profiles within seagrass canopies. Speed sensors were positioned at various heights $(5,10,20 \mathrm{~cm}$ from the bottom) within and above $(40 \mathrm{~cm}$ from the bottom) the meadow 
St. Joseph Bay, the conditions ranged from calm (SE $3 \mathrm{~m} \mathrm{~s}^{-1}$ ) to windy (W $8 \mathrm{~m} \mathrm{~s}^{-1}$ ) while during the Summerland Key deployment, conditions were relatively calm ( $\mathrm{S}-\mathrm{SE} 5 \mathrm{~cm} \mathrm{~s}^{-1}$ ). The first site was located in a protected embayment while the second site was in an exposed area mostly influenced by oceanic waves propagating onshore. The architecture of the canopies was characterized through measurements of shoot density ( $n=3,25 \times 25 \mathrm{~cm}$ random quadrats) and leaf length of all blades $(n=30)$ of 6 to 7 shoots along the side of the quadrat which was nearest to the SCUBA diver. The arrays of flow sensors were positioned within the $T$. testudinum beds at a minimum distance of $5 \mathrm{~m}$ from the canopy edge.

Vertical speed profiles were plotted based on speeds recorded at the various depths during a period of $3 \mathrm{~h}$ at Summerland Key and $6 \mathrm{~h}$ at St. Joseph Bay. The speeds were averaged over 28 min intervals ( 2 bursts of $14 \mathrm{~min}$ each as the data logger needed a minute to store the data collected during each burst). Turbulent energy spectra of potential energy (based on in situ high resolution water height measurements) and kinetic energy (based on in situ high resolution speed measurements) were analyzed by means of smoothed frequency spectral estimates obtained by Fourier transforming the number of points needed from the 8400 points collected, equivalent to 28 min of data (2 bursts), using a modified Matlab 4.2 c.1 (MathWorks, Inc, Natick, MA) program (see Gust et al. 1994). These Fourier transformations decompose a finite time series into a sum of sine and cosine functions of different frequencies to give the variance of a process (waves, speed) as a function of the frequency of the process (Denman 1975). The frequency spectra of waves and speed were plotted only for frequencies ranging from the fundamental to the Nyquist frequencies, i.e. in the interval of resolvable frequencies based on the $5 \mathrm{~Hz}$ data collection frequency. The spectral density distributions were normalized such that integration yielded the variance of the time-series signal. This approach provides an inherent test that the spectral evaluation procedures applied are accurate. Wave period $(T=1 / f)$ was calculated based on the wave frequencies $(f)$ in the wave spectra. As the time-series at each site generated data sets too large to present here, the data presented include $28 \mathrm{~min}$ of data that are representative of the general responses observed at each site.

As an estimate of the 'stability' of the water parcels above and within the meadow (or the tendency not to mix), a modified Richardson's number (Ri) was calculated for each burst of data (14 min) recorded at each site. Ri number is a ratio between stabilizing (difference in density between 2 water parcels) and destabilizing (current velocity) forces acting on a water body as shown in the following equation (Vogel 1994):

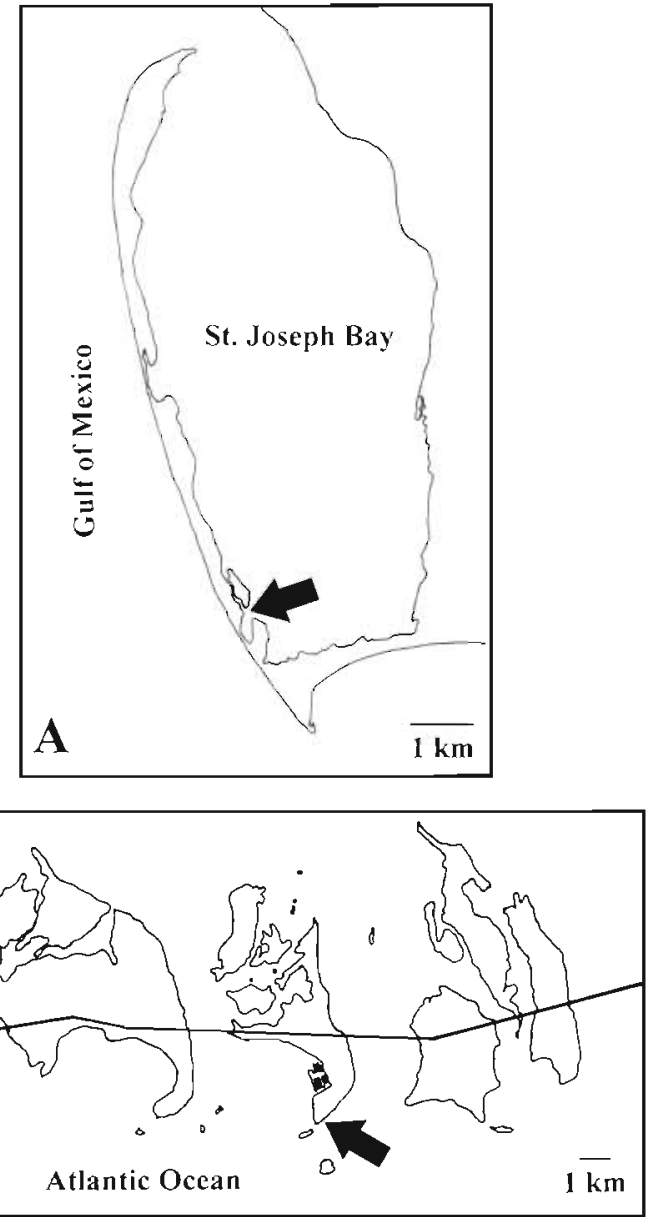

Fig. 2. Sites at which speed and depth were recorded within and above canopies of the seagrass Thalassia testudinum. (A) St. Joseph Bay is characterized as a tide-dominated environment and $(B)$ Summerland Key as a wave-dominated environment. The line in $B$ represents Highway 1 (road and bridges)

$$
\mathrm{Ri}=\frac{g\left(\frac{\mathrm{d} p}{\mathrm{~d} z}\right)}{\rho\left(\frac{\mathrm{d} U}{\mathrm{~d} z}\right)^{2}}
$$

where $g$ is the acceleration of gravity, $\mathrm{d} p / \mathrm{d} z$ the change in water density over depth, $\rho$ the water density and $\mathrm{d} U / \mathrm{d} z$ the change in velocity over depth. When studying water masses of different densities and a Ri number smaller than 0.25 is found, the water body is considered unstable (Vogel 1994).

The Ri number has been modified for this study by (1) using the change in seagrass density from the water column to the top of the meadow (instead of change in water density between 2 water masses) as the stabilizing force and (2) using the change in speed instead of change in velocity between the water column and the seagrass bed (i.e. our water flow data does not have a. 
vector/direction associated with it) as the destabilizing force. Therefore, $\mathrm{d} p / \mathrm{d} z$ was estimated as the seagrass density (no seagrasses in the water column to the biomass at the top of the meadow) divided by $0.2 \mathrm{~m}$ (height between the sensors above and at the top of the canopy from which speed data were obtained). Only the speeds at the seagrass-water column interface were used for this calculation. It was assumed that the seagrass density at the top of the meadow was the same as near the bottom, where the density of the shoots was measured. This is not necessarily true because the younger leaves do not reach the top of the meadow and, therefore, the highest leaf density is found near the bottom. Assuming that this vertical difference in density distribution is constant within the same species, the shoot density was used as an estimate to compare the effect of the different shoot densities observed at the sites in this study. Since the magnitude of the stabilizing force (shoot density) in this equation is different from the stabilizing force for which this equation was established (change in water density), the criteria that $\mathrm{Ri}<0.25$ determines unstable water parcels does not apply to the results here obtained.

\section{RESULTS}

The wave-dominated and tide-dominated sites are similar in the species colonizing the areas studied, the maximum leaf length, as well as the phase of the tidal cycle investigated (ebb) and the magnitude of the tidal fluctuation over the recording period. In contrast, the sites differ in hydrodynamic characteristics and plant density (Table 1).

\section{St. Joseph Bay (tide-dominated site)}

Mean values of flow above the seagrass meadow (40 $\mathrm{cm}$ above the bottom) lay in the range of 2.7 to
$4.5 \mathrm{~cm} \mathrm{~s}^{-1}$. The relatively weak currents at this site, were slowed even further within the meadow. Current speeds showed little change vertically through the meadow (Fig. 3A) when compared to speeds at the Summerland Key site. Windy conditions in the beginning of the recording period increased speeds in the water column above the plants but only slightly affected the average speed within the meadow, i.e. skimming flows (Fig. 3A).

The turbulent potential energy (TPE) at all frequencies in the St. Joseph Bay site (Fig. 3B) was in the lowest range $\left(1 \times 10^{-4}\right.$ to $\left.1 \times 10^{-5} \mathrm{~cm}^{2} \mathrm{~Hz}^{-1}\right)$ observed for sites in this study (compare Figs. $3 B$ \& $4 B$ ); it was mostly white noise (similar energy density at all frequencies). During a wind event during the deployment at St. Joseph Bay, energy in a relatively low frequency band (between $1 \times 10^{-2}$ and $5 \times 10^{-2} \mathrm{~Hz} ; T=100$ to $20 \mathrm{~s}$ ) increased when compared to the calm conditions (Fig. 3B). No defined peaks in a specific wave band frequency were observed during calm conditions (Fig. 3B). Wave height $(2 \mathrm{~cm})$ did not change much over time, even during the strong wind event due to the small fetch. The low TPE levels observed for St. Joseph Bay's wave spectra were also reflected in the relatively lower turbulent kinetic energy (TKE) levels in the canopy at this site (Fig. 3C,D) when compared to the wave-dominated site (Fig. 4C).

Speed frequency spectra within and above the seagrass bed in St. Joseph Bay during both calm (Fig. 3C) and windy (Fig. 3D) conditions indicate that TKE is lower within than above the canopy and further decreases towards the substratum. Most of the TKE in the water column was found at the lowest frequencies (Fig. 3C,D). The transfer of TKE from low to high frequencies within the canopy (represented by the slope of the spectra) was not as strong as in the water column above it (Fig. 3C,D). The turbulence dissipation rate for the spectra (imaginary line parallel to the portion of the spectra where a sharp decline in energy is observed indicating the dissipation of lower frequency turbulent eddies into smaller

Table 1. Biological and environmental characteristics of the study sites

\begin{tabular}{|lll|}
\hline & St. Joseph Bay & Summerland Key \\
\hline Seagrass species & Thalassia testudinum & Thalassia testudinum \\
Shoot density & $1147 \pm 33$ shoots $\mathrm{m}^{-2}$ & $539 \pm 40$ shoots $^{-2}$ \\
Maximum leaf length & $28 \pm 8 \mathrm{~cm}$ & $32 \pm 3 \mathrm{~cm}$ \\
Hydrodynamics & Tide-dominated & Wave-dominated \\
Plant movement & No flapping, blades & Back and forth flapping \\
& slightly bent over & Covering a $120^{\circ}$ angle \\
Tidal cycle during the deployments & Ebb & Ebb \\
Fluctuation in depth during deployments & 0.66 to $0.57 \mathrm{~m}$ & 0.68 to $0.59 \mathrm{~m}$ \\
Fetch & Calm (SE) $2.9 \mathrm{~km}$, windy (W) $0.2 \mathrm{~km}$ & (S) $0.9 \mathrm{~km}$, (SE) Atlantic Ocean \\
Wave height & $2 \mathrm{~cm}$ & $11 \mathrm{~cm}$ \\
Richardson numbers & Calm $106435 \pm 110738$, windy $4274 \pm 1335$ & $311 \pm 117$ \\
\hline
\end{tabular}



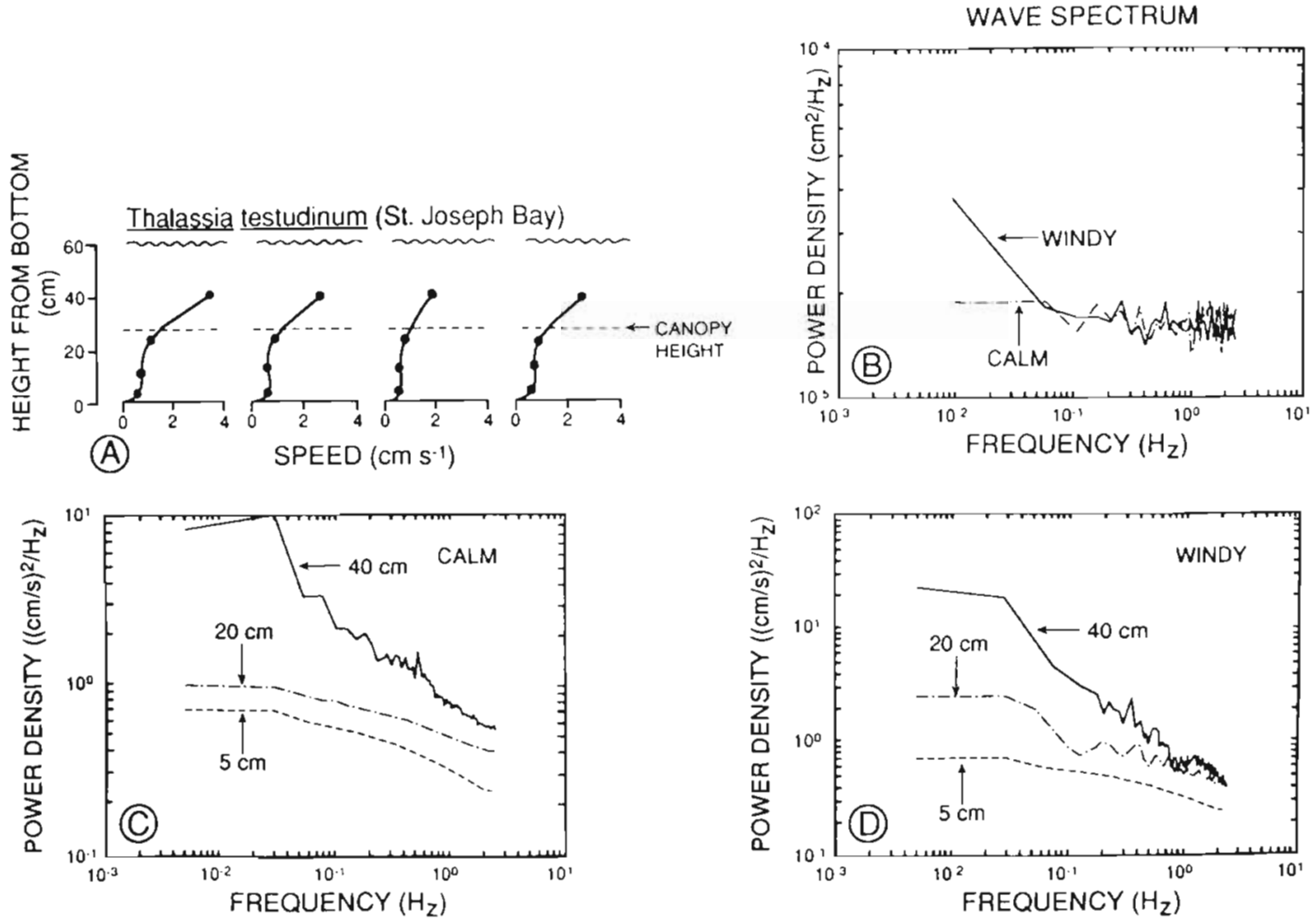

Fig. 3. (A) Speed profiles, (B) wave spectrum and (C and D) speed spectra (note different vertical scale) in a Thalassia testudinum canopy in a tide dominated environment (St. Joseph Bay) during calm and windy conditions. Each line represents 28 min of data recorded at a $5 \mathrm{~Hz}$ frequency and the time elapsed between profiles is $1 \mathrm{~min}$

high frequency eddies) generated from the data collected in and above the seagrasses did not show the expected universal spectral dissipation rate observed in wall-bounded shear flow (like in unvegetated areas) which is usually $-5 / 3$. Instead, a slope of approximately $-3 / 2$ (imaginary line parallel to the spectra between 0.1 and $1 \mathrm{~Hz}$ ) was observed above the meadow and nearly white noise shapes (similar energy levels at all frequencies) inside the seagrass bed. Turbulent energy in the water column penetrated deeper into the meadow when it was exposed to windy rather than calm conditions (Fig. 3C,D). Independently of the wind conditions, TKE levels were always higher at $20 \mathrm{~cm}$ from the bottom than at $5 \mathrm{~cm}$ (Fig. 3C,D). Additionally, TKE at all turbulence frequencies at $5 \mathrm{~cm}$ from the bottom was independent of the speed in the water column.

\section{Summerland Key (wave-dominated site)}

Mean velocities above the meadow $(40 \mathrm{~cm}$ above the bottom) were between 12 and $17 \mathrm{~cm} \mathrm{~s}^{-1}$. Speed tended to decrease towards the bottom (Fig. 4A), but the slowing of water movement by the seagrass bed was not as evident as for St. Joseph Bay (compare siopes in
Figs. 3A \& 4A). Speeds progressively decreased from $40 \mathrm{~cm}$ (water column), through the meadow, to $5 \mathrm{~cm}$ above the bottom. Little change in the shape of the speed profiles was observed during the $3 \mathrm{~h}$ this timeseries was recorded (Fig. 4A).

Wind-generated waves of approximately $11 \mathrm{~cm}$ height dominated at the Summerland Key site. Most of the TPE was concentrated in the frequency band between 0.06 and $0.8 \mathrm{~Hz}(T=16.7$ and $1.3 \mathrm{~s}$ ) with a peak at $0.25 \mathrm{~Hz}(T=4 \mathrm{~s}$; Fig. $4 \mathrm{~B})$, which is characteristic for wind generated gravity waves (Brown et al. 1989).

Speed frequency spectra for the seagrass canopy at Summerland Key indicate that levels of TKE in the water column and at the top of the vegetation are similar to each other (Fig. 4C) while TKE is lower at the bottom of the canopy ( $5 \mathrm{~cm}$ from the bottom). As observed for St. Joseph Bay, levels of TKE within the canopy were always higher at $20 \mathrm{~cm}$ than at $5 \mathrm{~cm}$ from the bottom (Fig. 4C). The slopes of the TKE spectra in Fig. $4 \mathrm{C}$ suggest that the turbulence dissipation rate was similar in the water column and within the canopy. A peak in TKE was observed in the frequency band between 0.2 and $0.3 \mathrm{~Hz}$ ( $T=5$ and $3.3 \mathrm{~s}$, Fig. $4 \mathrm{C}$ ), which was also the band in which most of the TPE was concentrated (Fig. 4B). 
Modified Ri numbers which represent the potential for mixing of the water within and above the meadows (the smaller the Ri number, the higher the tendency for the water above and within the meadow to mix), confirm the trends observed in Figs. 3C,D \& 4C. The highest Ri numbers (106435 \pm 110738$)$ were found under calm conditions in the dense bed (St. Joseph Bay). Intermediate values $(4274 \pm 1335)$ were found under windy conditions at the same site and the lowest Ri numbers $(31.1 \pm 117)$ were observed at the wave domi-
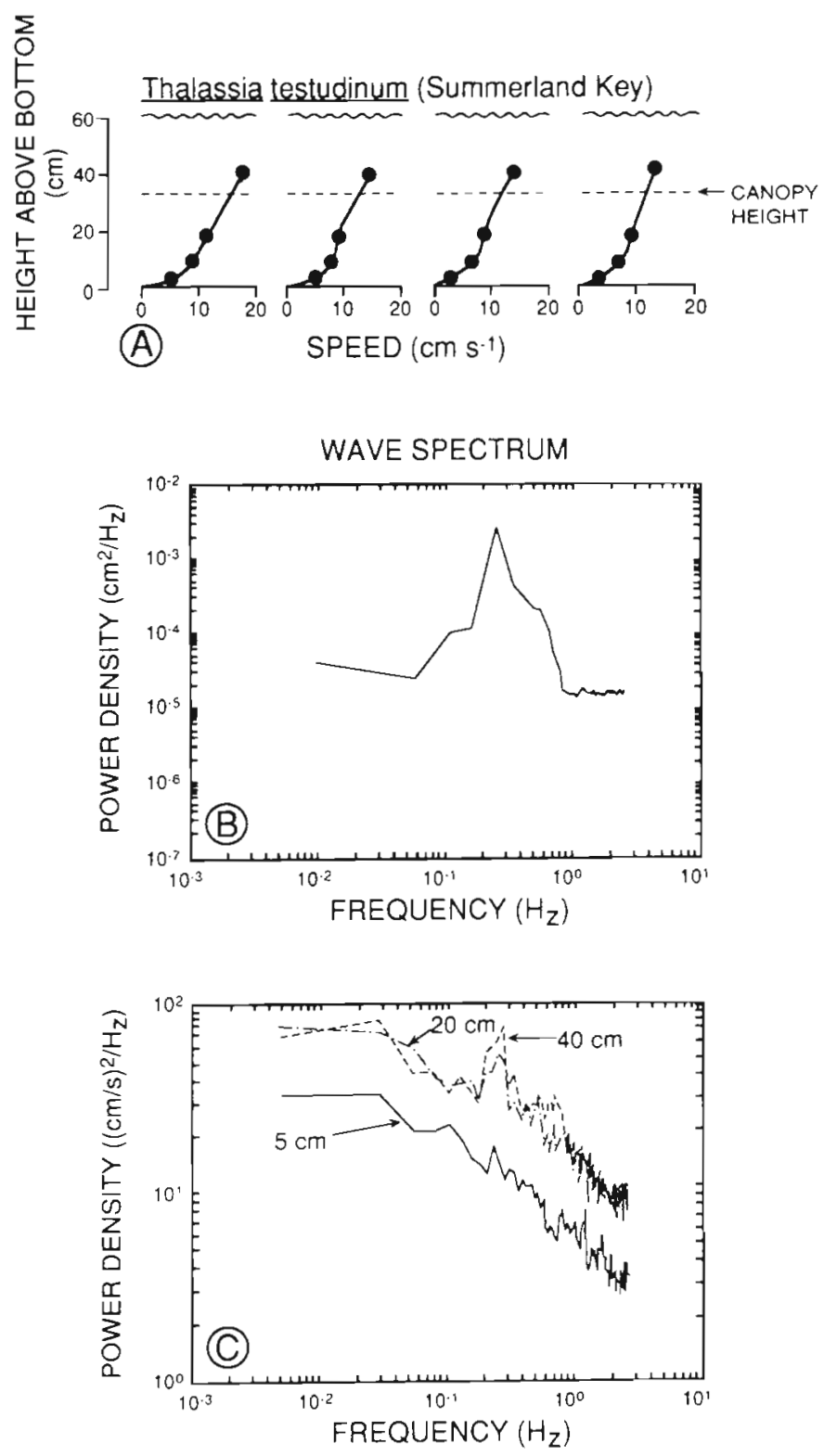

Fig. 4. (A) Speed profiles, (B) wave spectrum and (C) speed spectra in a Thalassia testudinum canopy in a wave-dominated environment (Summerland Key). Each line represents 28 min of data recorded at a $5 \mathrm{~Hz}$ frequency and the time elapsed between profiles is 1 min nated site. These values show that during windy conditions in St. Joseph Bay the water within and above the vegetation was 24 times more likely to become mixed than under calm conditions. The destabilizing forces under windy conditions at St. Joseph Bay (tidedominated site) were still 14 times more stable than. those found offshore of Summerland Key (wave domjnated site). At this site, the Ri number tended to increase (increased stability) as the ebb tide progressed and with it the water level and speed above the meadow declined.

\section{DISCUSSION}

The majority of previous observations regarding flow through plant meadows come from theoretical models (Wayne 1975, Eckman 1990), from unidirectional flow experiments in flumes (e.g. Fonseca et al. 1982, Gambi et al. 1990, Fonseca \& Cahalan 1992, Nepf et al. 1997) or from waves superimposed on unidirectional flow also in a flume (e.g. Heller 1987). Due to the advancement in technology, more studies are now preformed in situ (see Ackerman \& Okubo 1993, Worcester 1995, Grizzle et al. 1996, Koch 1996). The results from the present field study confirm previous flume and field findings that seagrass canopies attenuate wave energy and decrease current velocity

However, the present study also shows that the reduction of current speed and turbulent energy vertically through seagrass beds and, consequently, reduced mixing of the water masses within and above the meadow, depend on the hydrodynamic condition (tides vs waves) prevailing in the seagrass habitat.

\section{Hydrodynamic conditions in a seagrass meadow exposed to unidirectional flows (tides)}

In the tide-dominated environment (St. Joseph Bay), the speed profiles (Fig. 3A) maintained relatively conStant values over depth within the canopy with only slight changes at the top of the meadow during windy conditions (this can also be seen in the speed frequency spectra for calm and windy conditions). Visual observations confirmed that blades in the tide-dominated environment tended to slightly bend over in the direction of the tidal current forming a sealed structure over which the currents flowed (skimming flows). These skimming flows were also observed by Fonseca et al. (1982), Ward et al. (1984) and Gambi et al. (1990) as a result of the leaves bending over when exposed to unidirectional flows. The high TKE above the canopy $(40 \mathrm{~cm}$ from the bottom) when compared to that at the 
top of the canopy ( $20 \mathrm{~cm}$ from the bottom) is characteristic of such skimming flows (Eckman 1983). Conse quently, skimming flows reduce the turbulence intensity within the meadow as well as the mixing between the water masses above and within the meadow llarge Ri number). As a result, suspended particles within the canopy can be deposited (Ward et al. 1984). The low mixing between the water above and within the meadow can be quickly reversed by the onset of windy conditions (see the decline in Ri number for windy conditions in St. Joseph Bay).

\section{Hydrodynamic conditions in a seagrass meadow exposed to oscillatory flows (waves)}

In contrast to the findings for the tide-dominated site (St. Joseph Bay), in Summerland Key, oscillatory flows generated by waves allow blades to flap back and forth at the frequency of the waves, 'opening' (leaves in the upright position) and 'closing' (leaves bent over) the meadow. During the short period the meadow is 'closed' (this period depends on the wave fequency), i.e. the leaves are bent over, skimming flows may develop but these are quickly disrupted as the meadow 'opens' again. As a result, skimming flows are not allowed to fully develop and the interaction between the water masses within and above the seagrass meadow increases (low $\mathrm{Ri}$ numbers). The increased tendency for water masses to mix under wave-dominated conditions was not only observed at the wave-dominated site (where speed profiles, speed spectra and Ri number showed a less steep gradient between speeds above and within the canopy) but also when the dense meadow in St. Joseph Bay was exposed to slightly higher oscillatory flows during windy conditions. The small increase in waves in St. Joseph Bay generated higher levels of turbulence at the top of the dense meadow (perhaps due to increased blade flapping or a reduced capacity to attenuate water flow under oscillatory motion). These findings suggest that hydrodynamic conditions prevailing in the habitat colonized by seagrasses play a major role in determining the turbulent energy and mixing found within seagrass beds. A consequence would be that higher shear stress could be observed near the bottom of wave-dominated sites and, consequently, more particles could be maintained in suspension than under tide-dominated/unidirectional flow conditions.

The TPE at the wave-dominated site was concentrated in the 0.06 to $0.9 \mathrm{~Hz}$ frequency (16 to $1.1 \mathrm{~s}$ period) band representing wind generated gravity waves. These wave frequencies are lower than those used by Fonseca \& Cahalan (1992) in a flume experiment (1.4 to $2.5 \mathrm{~Hz}$ ) and those measured by Ackerman
\& Okubo (1993) in a sparse (approximately 91 shoots $\mathrm{m}^{-2}$ ) Zostera marina bed in situ. Ackerman \& Okubo (1993) suggested that the concentration of energy they observed at frequencies between 0.125 and $0.156 \mathrm{~Hz}$ was not caused by ambient flow conditions but were generated by the movement of the plants (monami). The wave pattern in an aquatic environment should allow orbital motion to be distinguished from tidal flows in the speed frequency spectra. This can be seen in the form of a peak in the speed frequency spectra (wave energy added to the speed energy) at the dominant wave frequency. Such a peak occurs in the speed frequency spectra in the water column above the meadow ( $40 \mathrm{~cm}$ from the bottom) as well as at the top of the meadow ( $20 \mathrm{~cm}$ from the bottom) in Summerland Key (Fig. 4C). The upper portion of the wave-exposed meadow showed selectively stronger reduction of turbulent energy in this dominant wave frequency band when compared to other non-dominant frequencies. This reduction in turbulent energy may be due to the loss of momentum due to the flapping of leaves at the frequencies of the wave orbital motion. Therefore, in this study, the peak of energy observed in the speed spectra was probably due to the wind-generated waves and not the movement of the plants. With increasing depth, the signal of the orbital motion was attenuated within the canopy (peak is smaller at $20 \mathrm{~cm}$ from the bottom than at $40 \mathrm{~cm}$ ), and at the bottom of the meadow ( $5 \mathrm{~cm}$ from the bottom), the velocity frequency spectra merely showed the shape of a turbulent flow (i.e. the peak observed at 20 and $40 \mathrm{~cm}$ from the bottom was strongly reduced at $5 \mathrm{~cm}$ ).

\section{Shoot ('obstruction') density and hydrodyamic characteristics of seagrass meadows}

Turbulence intensity of flat beds covered with stiff roughness elements (like the lower portion of some seagrass shoots) and exposed to unidirectional (tidal) flows depends on the density of the 'obstructions'. The highest turbulence levels are found at low 'obstruction' densities (Eckman 1990, Nepf et al. 1997). Since turbulence is also a function of water flow, higher 'obstruction' densities will lead to a reduction in turbulence due to the attenuation in current velocity within high densities of 'obstructions' (Nepf 1999). Skimming flows above seagrass meadows as those found in St. Joseph Bay are another mechanism for generating low turbulence environments within the vegetation (high turbulence above the plants). In contrast, flows through the plant canopies generate high turbulence within the vegetation. In this aspect, the high density of the bed in St. Joseph Bay may have contributed to the deflection of the water flow over the meadow although Fonseca et al 
(1982) showed that less dense meadows like the one studied adjacent to Summerland Key also bend over in unidirectional flows causing the water to skim over the less dense meadows. If the less dense bed had been exposed to unidirectional skimming flows, it would probably also have generated less turbulence and reduced mixing within the vegetation. Ackerman \& Okubo (1993) observed such reduced mixing in a Zostera marina meadow with relatively low shoot density (approximately 91 shoots $\mathrm{m}^{-2}$ ), but in our study, the leaves of the low shoot density seagrass bed exposed to oscillatory flows (wave-dominated site) moved back and forth allowing the water to flow through the meadow instead of over it (i.e. no skimming flows due to flaping of blades). In contrast, the dense bed exposed to tides showed skimming flows but under windy conditions the response of the dense meadow became more similar to that observed in the wave-dominated site with lower shoot density (compare Figs. 3A,B \& 4C). This pattern is also seen in the smaller Ri number and suggests that density may have some effect on the magnitude of attenuation of water flow and turbulence while the pattern of attenuation (stronger attenuation vertically through the meadow or only near the bottom) is closely related to the hydrodynamic conditions in the seagrass habitat.

\section{Vertical dissipation of turbulent energy in seagrass beds}

In flows near a boundary, like a sediment or leaf surface, turbulent energy in eddies dissipates from lower frequencies (larger eddies) to higher frequencies (smaller eddies) at a rate of $-5 / 3$. Under the windy conditions in St. Joseph Bay, this rate was smaller than that observed for Summerland Key. The lower rate of eddy diffusivity could be due to the hydrodynamic conditions prevailing at the 2 sites. In the wave-dominated site, the rate of turbulent dissipation in the water column $140 \mathrm{~cm}$ above the bottom) was similar to that at the top of the meadow ( $20 \mathrm{~cm}$ above the bottom). The similarity in energy dissipation suggests little attenuation of water flow by the top of the meadow under oscillatory flows and/or the transfer of the flow characteristics generated by the motion of the leaves into the water column. These processes lead to a well mixed area at the upper portion of the meadow and/or transfer of water from among the vegetation into the water column.

\section{Mixing of water masses above and within seagrass meadows}

The tendency for water masses above and within the meadow to mix was weaker where shoot density was high and the vegetation was exposed to tidedominated conditions than where shoot density was lower and the vegetation was exposed to wave-dominated conditions. Ri numbers showed that, even in dense meadows (1147 shoots $\mathrm{m}^{-2}$ ) exposed to small waves (St. Joseph Bay), the water above and within the vegetation can become destabilized resembling the conditions observed at the wave-dominated site. At Summerland Key (little change in wave action over time), Ri numbers increased as the ebb tide progressed and water levels decreased. The change in $\mathrm{Ri}$ number over time can be explained by the decrease in speed (destabilizing force) as the ebb tide progressed but could also be linked to the change in water depth. In future studies using the modified Ri number to estimate the stability of water parcels above and within seagrass meadows, the change in seagrass shoot density over the tidal cycle (as water depth decreases and the meadow is compressed) needs to be taken into consideration. We assumed the seagrass density to be constant over time and over depth, but as the water level falls during the ebb tide the blades tend to bend over and therefore make the seagrass bed more dense (more leaf area per volume) at the top of the meadow. If this had been taken into consideration in this study, the $\mathrm{Ri}$ numbers would have increased even more (more stability and less mixing between the water parcels) as the tidal level fell over time. This could have important consequences for water mixing within seagrass beds.

In summary, the hydrodymamic microclimate, and consequently mixing within seagrass beds, strongly depends on the hydrodynamic forces (waves and currents) acting on the plants.

Under unidirectional flows (tides), the water tends to move over the meadow (skimming flows). Under these conditions, the leaves are bent over in the direction of the flow for several hours (until the tide turns) and mixing between the water above and within the meadow is minimized. In contrast, under oscillatory flows (waves) the leaves flap back and forth at the frequency of the waves (milliseconds to seconds), thus not allowing the skimming flows to develop. As a result, mixing between water masses above and within waveexposed meadow is high. Additionally, dissipation of turbulent energy at the top and above the meadow exposed to wave-dominated conditions was similar. This similarity in pattern could be attributed to little attenuation of flow at the top of the meadow or due to the transfer of flow characteristics from the meadow to the water column. Further studies are necessary to clarify which of these explanations applies to seagrass meadows in oscillatory flows.

Modified Ri numbers seem to be appropriate to obtain a quick and easy estimate of mixing between 
water masses above and within seagrass meadows but experiments quantifying the mass transfer between seagrasses and the water above them are needed to confirm this. The Ri numbers here calculated suggest that seagrass shoot density may affect the magnitude of exchange between the water column and the seagrass bed (high shoot density meadows seem to have a stronger velocity gradient between the vegetation and the water column then low shoot density meadows) while the hydrodynamic conditions prevailing in the seagrass habitats (waves, tides) change the pattern of vertical flow attenuation (stronger near the top of the meadow when skimming flows develop under tidedominated conditions and weaker flow attenuation near the top when blades flap under wave-dominated conditions).

Acknowledgements. Financial support was provided by the United States Geological Survey (Florida Wetlands Project coordinated by Dr Rick Stumpf), the Conselho Nacional de Desenvolvimento Científico e Tecnológico (Brazil) and the Knight Fellowship. Dr Mark Luther contributed through lengthy discussions. Walter Bowles and Richard Eilers helped during the field deployments. Drs Clinton Dawes, Michael Durako, Mark Fonseca, Pamela Hallock-Muller, Albert Hine, Mimi Koehl, John Ogden and an anonymous reviewer are thanked for their comments on the manuscript.

\section{LITERATURE CITED}

Ackerman JD, Okubo A (1993) Reduced mixing in a marine macrophyte canopy. Funct Ecol 7:305-309

Anderson SM, Charters AC (1982) A fluid dynamics study of seawater flow through Gelidium nudifrons. Limnol Oceanogr 27:399-412

Brown J, Collins A, Park D, Phillips J, Rothery D, Wright J (1989) Waves, tides and shallow-water processes. Pergamon Press, New York

Burke RW (1982) Free surface flow through salt marsh grass. PhD thesis, Massachussetts Institute of Technology/Woods Hole Oceanographic Institute, WHOI-82-50

Cambridge ML, McComb AJ (1984) The loss of seagrasses in Cockburn Sound, Western Australia. I. The time course and magnitude of seagrass decline in relation to industrial development. Aquat Bot 20:229-243

Clarke SM (1987) Seagrass-sediment dynamics in Holdfast Bay: summary. Safish 11:4-10

Denman KL (1975) Spectral analysis: a summary of theory and techniques. Fish Mar Ser Res Dev Tech Rep

Eckman JE (1983) Hydrodynamic processes affecting benthic recruitment. Limnol Oceanogr 28:241-257

Eckman JE (1990) A model of passive settlement by planktonic larvae onto bottoms of differing roughness. Limnol Oceanogr 35:887-901

Fonseca MS, Cahalan JA (1992) A preliminary evaluation of wave attenuation by four species of seagrasses. Estuar Coast Shelf Sci 35:565-576

Fonseca MS, Fisher JS (1986) A comparison of canopy friction and sediment movement between four species of seagrasses with reference to their ecology and restoration. Mar Ecol Prog Ser 29:15-22
Fonseca MS, Kenworthy (1987) Effects of current on photosynthesis and distribution of seagrasses. Aquat Bot 27 : $59-78$

Fonseca MS, Fisher JS, Zieman JC, Thayer GW (1982) Influence of the seagrass Zostera marina (L) on current flow Estuar Coast Shelf Sci 15:351-364

Gambi MC, Nowell ARM, Jumars PA (1990) Flume observations on flow dynamics in Zostera marina (eelgrass) beds. Mar Ecol Prog Ser 61:159-169

Gerard V, Mann KH (1979) Growth and production of Laminaria longicuris populations exposed to different intensities of water movement. J Phycol 15:33-41

Giesen WBJT, van Katwijk MM, den Hartog C (1990) Eelgrass condition and turbidity in the Dutch Wadden Sea Aquat Bot 37:71-85

Grizzle RE, Short FT, Newell CR, Hoven H, Kindblom L (1996) Hydrodynamically induced synchronous waving of seagrasses: monami and its possible effects on larval mussel settlement. J Exp Mar Biol Ecol 206:165-177

Gust $G$ (1988) Skin friction probes for field applications J Geophys Res 93:14121-14132

Gust G (1991) Fluid velocity measurement instrument. US Patent no. 4996122

Gust G, Michaels AF, Johnson R, Deuser WG, Bowels W (1994) Mooring line motions and sediment trap hydromechanics: in situ intercomparison of three common deployment designs. Deep-Sea Res 41:831-857

Heller DY (1987) Sediment transport through seagrass beds MSc thesis, University of Virginia

Kenworthy WJ, Zieman JC, Thayer GW (1982) Evidence for the influence of seagrasses on the benthic nitrogen cycle in a coastal plain estuary near Beaufort, North Carolina (USA). Oecologia (Berl) 54:152-158

Koch EW (1994) Hydrodynamics, diffusion-boundary layers and photosynthesis of the seagrasses Thalassia testudinum and Cymodocea nodosa. Mar Biol 118:767-776

Koch EW (1996) Hydrodynamics of a shallow Thalassia testudinum bed in Florida, USA. In: Kuo J, Phillips RC, Walker DI, Kirkman H (eds) Seagrass biology: proceedings of an international workshop. The Univ of Western Australia, Perth, p 105-109

Koehl MAR, Alberte RS (1988) Flow, flapping and photosynthesis of Nereocystis luetkeanna: a functional comparison of undulate and flat blade morphologies. Mar Biol 99 435-444

Leonard LA, Luther ME (1995) Flow hydrodynamics in tidal marsh canopies. Limnol Oceanogr 40:1471-1484

Nepf HM (1999) Drag, turbulence and diffusion in flow through emergent vegetation. Water Resour Res 35:479-489

Nepf HM, Sullivan JA, Zavistoski RA (1997) A model for diffusion within emergent vegetation. Limnol Oceanogr 42 : 1735-1745

Orth RJ, Moore KA (1983) Chesapeake Bay: an unprecedented decline in submerged aquatic vegetation. Science 222:51-53

Short FT (1987) Effects of sediment nutrients on seagrasses: literature review and mesocosm experiment. Aquat Bot 27:41-57

van Keulen M (1997) Water flow in seagrass ecosystems. PhD dissertation, Murdoch University, Western Australia

Verduin JJ (1996) Interactions of the species Amphibolis antarctica with the hydrodynamic environment and their implications for pollination ecology. $\mathrm{PhD}$ thesis, University of Western Australia, Perth

Vogel S (1994) Life in moving fluids. Princeton University Press, Princeton

Ward LG, Kemp WM, Boynton WR (1984) The influence of 
waves and seagrass communities on suspended particles in an estuarine embayment. Mar Geol 59:85-103

Wayne CJ (1975) Sea and marsh grasses: their effect on wave energy and nearshore sand transport. MSc thesis, Florida State University, Tallahassee

Wheeler WN (1980) Effect of boundary layer transport on the fixation of carbon by the giant kelp Macrocystis pyrifera. Mar Biol 56:103-110

Worcester SE (1995) Effects of eelgrass beds on advection and

Editorial responsibility: Gordon Thayer (Contributing Editor), Beaufort, North Carolina, USA turbulent mixing in low current and low shoot density environments. Mar Ecol Prog Ser 126:223-232

Zimmerman RC. Alberte RS (1991) Light requirements of temperate seagrasses. In: Kenworthy JW, Haunert DE (eds) The light requirements of seagrasses. Proceedings of a workshop to examine the capacity of water quality criteria, standards and monitoring programs to protect seagrasses. NOAA Technical Memorandum NMFS-SEFC287, Beaufort, NC, p 26-37

Submitted: November 15, 1997; Accepted: February 15, 1999 Proofs received from author(s): July 13, 1999 